\title{
Óleo essencial de Baccharis tridentata Vahl: composição química, atividade antioxidante e fungitóxica, e caracterização morfológica das estruturas secretoras por microscopia eletrônica de varredura
}

\author{
SOUZA, S.P. ${ }^{1}$; CARDOSO, M.G. ${ }^{1 *}$; SOUZA, P.E. ${ }^{2}$; GUIMARÃES, L.G.L. ${ }^{1}$; ANDRADE, J. ${ }^{1}$; MALLET, A.C.T. ${ }^{3}$ \\ NELSON, D.L. ${ }^{4}$ \\ ${ }^{1}$ Departamento de Química, ${ }^{2}$ Departamento de Ciência dos Alimentos, ${ }^{3}$ Departamento de Fitopatologia, Universidade \\ Federal de Lavras, CEP: 37200-000, Lavras-Brasil ${ }^{4}$ Departamento de Alimentos, Faculdade de Farmácia, \\ Universidade Federal de Minas Gerais, CEP: 31270-901, Belo Horizonte-Brasil *mcardoso@dqi.ufla.br
}

RESUMO: Este trabalho teve como objetivos avaliar a composição química do óleo essencial de Baccharis tridentata Vahl, as atividades antioxidante e fungitóxica, e estudar a morfologia das estruturas secretoras do óleo essencial presentes na superfície foliar por meio de microscopia eletrônica de varredura (MEV). A extração do óleo essencial foi realizada por hidrodestilação, as análises quantitativas e qualitativas foram executadas por meio de cromatografia em fase gasosa com detector de ionização de chamas (FID) e acoplada à espectrometria de massas, respectivamente. A atividade antioxidante foi realizada empregando-se os métodos de redução do radical estável DPPH e o ensaio de oxidação do sistema $\beta$-caroteno/ácido linoleico. As atividades fungitóxicas foram avaliadas utilizando o teste bioanalítico in vitro, sobre a inibição do crescimento micelial dos fitopatógenos Fusarium oxysporum, Colletotrichum gloeosporioides e Rhizoctonia solani. A composição química revelou a presença de 28 compostos, sendo o $\alpha$-tujeno $(22,93 \%)$ o constituinte majoritário; não foi observada atividade antioxidante por meio dos ensaios utilizados, no entanto, observou-se atividade fungitóxica sobre o crescimento micelial dos fitopatógenos estudados. Já os estudos da superfície foliar por MEV revelaram a presença de tricomas glandulares em ambas as superfícies abaxial e adaxial.

Palavras-chave: óleo essencial, Baccharis, atividade biológica

\begin{abstract}
Baccharis tridentata Vahl essential oil: chemical composition, and antioxidant and fungitoxic activities and morphological characterization of secretory structures by scanning electron microscopy. This study aimed to evaluate the chemical composition and the antioxidant and fungitoxic activities of Baccharis tridentata essential oil, as well as to study the morphology of its secretory structures present on the leaf surface by scanning electron microscopy (SEM). The essential oil was extracted by hydrodistillation; the quantitative and qualitative analyses were performed on a gas chromatograph equipped with a flame ionization detector (FID) and coupled to a mass spectrometer, respectively. The antioxidant activity was determined by the methods of reduction of the DPPH stable radical and oxidation of the $\beta$-carotene/linoleic acid system. Fungitoxic activities were assessed by the in vitro bioanalytical test on the inhibition of the mycelial growth of the plant pathogens Fusarium oxysporum, Colletotrichum gloeosporioides and Rhizoctonia solani. The chemical composition revealed the presence of 28 compounds, with $\alpha$-thujene (22.93\%) as the major constituent. No antioxidant activity was observed in the tests used; however, there was fungitoxic activity against the mycelial growth of plant pathogens. Leaf surface studies by SEM revealed the presence of glandular trichomes on both abaxial and adaxial surfaces.
\end{abstract}

Key words: essential oil, Baccharis, biological activity

\section{INTRODUÇÃO}

Os óleos essenciais, constituintes voláteis orgânicos responsáveis pela fragrância de muitas

plantas, são compostos que vêm despertando grande interesse nas pesquisas, por serem potencialmente

Recebido para publicação em 06/12/2009

Aceito para publicação em 10/05/2011

Rev. Bras. PI. Med., Botucatu, v.13, n.4, p.456-466, 2011. 
úteis no controle fitossanitário, propiciando o desenvolvimento de técnicas que procuram diminuir os efeitos negativos de agentes oxidantes, radicais e micro-organismos que causam prejuízos nas indústrias de alimentos e na agricultura.

Estes desempenham diferentes e importantes papéis nos vegetais como na defesa ao ataque de patógenos, animais herbívoros, podendo também agir na atração de organismos benéficos. Devido às diferentes atividades biológicas apresentadas por estes compostos, há crescente número de estudos, visando verificar a atividade antimicrobiana e antioxidante dos mesmos (Simões et al., 2007).

Estudos toxicológicos com animais empregando os antioxidantes sintéticos mais utilizados na indústria alimentícia, BHA (butil-hidroxianisol), BHT (butil-hidroxi-tolueno), PG (galato de propila) e o TBHQ (tert-butil-hidroquinona), têm demonstrado a possibilidade destes compostos apresentarem efeitos carcinogênicos (Botterweck et al., 2000). Desta forma, pesquisas têm sido dirigidas no sentido de encontrar produtos naturais, que assim como os tocoferois e os ácidos orgânicos, que são antioxidantes de origem natural, possam permitir a substituição dos antioxidantes sintéticos ou fazer associações com estes, com o intuito de diminuir os teores nos alimentos (Ramalho \& Jorge, 2006).

Em muitos estudos têm sido demonstrado o potencial dos óleos essenciais como antioxidantes de origem vegetal. Vardar-Ünlü et al. (2003) demonstraram a atividade antioxidante do óleo essencial de Thymus pectinatus. Ebrahimabadi et al. (2010) demonstraram a atividade antioxidante do óleo essencial de Stachys inflata e dos constituintes majoritários linalol e $\alpha$-terpineol.

$\mathrm{Na}$ agricultura, por muitos anos uma variedade de diferentes compostos químicos sintéticos como os benzimidazois, hidrocarbonetos aromáticos e inibidores da biossíntese de esterois têm sido muitas vezes utilizados no controle de doenças de plantas. No entanto, o uso destes produtos sintéticos para o controle de doenças causadas por fungos e bactérias em plantas como antracnose, mancha marrom, mancha bacteriana, pinta bacteriana e contra a deterioração de frutos e vegetais no período de pós-colheita, tem sido restringido devido aos seus efeitos carcinogênicos, teratogênicos, alta e aguda toxicidade residual, longo período de degradação, poluição ambiental entre outros (Unnikrishnan \& Nath, 2002). De acordo com Dianz et al. (2002), outro problema é o desenvolvimento de resistência em decorrência do uso contínuo destes produtos em populações de fitopatógenos.

Um grande número de pesquisas relata atividades de diversos óleos essenciais sobre microorganismos fitopatogênicos, principalmente sobre patógenos causadores de perdas em frutos e vegetais em período de pós-colheita. Avaliando o efeito fungitóxico de 37 óleos essenciais sobre Fusarium verticillioides, F. proliferatume F. graminearum, Velluti et al. (2004) observaram atividade fungitóxica para os óleos de orégano (Origanum vulgare), cinamomo (Melia azedarach) e cravo-da-índia (Syzygium aromaticum). Kordali et al. (2007) avaliaram as atividades de vários monoterpenos oxigenados, compostos presentes em vários óleos essenciais, sobre a inibição do crescimento micelial de 31 fungos fitopatogênicos, e encontraram valores de inibição para o $\beta$-citronelol e para o nerol superiores aos apresentados pelo fungicida Benomil. Bajpai et al. (2007), estudando o efeito fungitóxico do óleo essencial de Metasequoia glyptostroboides, sobre fungos pertencentes ao gênero Fusarium, demonstraram que essa planta pode ser utilizada pelas agroindústrias como fungicida natural em alternativa ao uso de produtos químicos sintéticos, no tratamento de muitos micro-organismos fitopatogênicos causadores de grandes prejuízos na agricultura.

O gênero Baccharis é constituído por mais de 500 espécies distribuídas em vários países da América do Sul, ocupando principalmente regiões mais elevadas. No Brasil estão descritas 120 espécies incluídas neste gênero, estando a maior parte delas localizadas na região Sudeste. As espécies pertencentes a este gênero são geralmente arbustos como a carqueja, a vassoura ou a vassourinha e medem em média de 0,5 a $4,0 \mathrm{~m}$ de altura (Giuliano, 2001).

Entre as espécies mais pesquisadas encontram-se B. megapotamica, B. incarum, B. trimera, $B$. trinervis, B. salicifolia, B. crispa, B. coridifolia, $B$. dracunculifolia, $B$. grisebachii e $B$. tricuneata. No entanto, sobre a espécie Baccharis tridentata Vahl. (Asteraceae), que se trata de um subarbusto de 0,52,0 $\mathrm{m}$ de altura (Barroso, 1986), foi identificado apenas um trabalho, desenvolvido por Ferracini et al. (1995); no qual os mesmos relatam a caracterização química do óleo essencial. Agostini et al. (2005), estudando os óleos essenciais de diversas espécies de Baccharis, encontraram entre os constituintes majoritários dessas espécies os compostos $\alpha$-pineno, $\beta$-pineno, espatulenol e o limoneno. Lago et al. (2008), estudando a composição de seis espécies de Baccharis coletadas na região Sudeste do Brasil, relataram a predominância dos monoterpenos $\alpha$ e $\beta$ pineno e dos sesquiterpenos $\gamma$-cadineno, germacreno$D$, biciclogermacreno, $\alpha$-humuleno, aromadendreno e (E)-cariofileno na composição destes óleos essenciais. Trabalhos com várias espécies de Baccharis mostraram que estas possuem atividades microbiológicas. O óleo essencial de Baccharis trimera apresentou atividade antimicrobiana sobre $S$. aureus e E. coli (Avancini et al., 2000). A atividade

Rev. Bras. PI. Med., Botucatu, v.13, n.4, p.456-466, 2011. 
antimicrobiana de Baccharis nitida, foi observada sobre as bactérias $S$. aureus e $P$. aeruginosa, bactérias Gram positiva e Gram negativa, respectivamente (Rangel et al., 2001).

Apesar de haver vários estudos com a caracterização química dos óleos essenciais de plantas do gênero Baccharis, poucos estudos foram realizados para verificar suas atividades biológicas. Flores et al. (2009) encontraram uma moderada atividade antibacteriana contra bactérias Gram positivas para o óleo essencial de Baccharis salicifolia, com CMI (concentração mínima inibitória) variando entre 0,47 e 0,94 $\mu \mathrm{g} \mathrm{mL}^{-1}$ Já o óleo essencial de Baccharis dracunculifolia apresentou atividade antiprotozoária sobre Leishmania donovani, com IC igual a $42 \mu \mathrm{g} \mathrm{mL}^{-1}$, apresentando também atividade antihelmíntica sobre Schistosoma mansoni com concentrações a partir de $10 \mu \mathrm{g} \mathrm{mL}^{-1}$, por outro lado este óleo essencial não apresentou atividade antimicrobiana sobre leveduras pertencentes ao gênero Candida (Parreira et al., 2010).

De acordo com Lewinsohn et al. (1998), apesar do avanço no conhecimento das propriedades biológicas e farmacológicas dos óleos vegetais, sabese pouco sobre a morfologia das estruturas celulares ou órgãos envolvidos na produção nos vegetais. Várias espécies de Baccharis possuem tricomas tectores e glandulares na epiderme de folhas e caules (Hellwing, 1992). Budel et al. (2004 b) encontraram tricomas glandulares e tectores pluricelulares na epiderme caulinar de Baccharis cylindrica (Less.) DC. Nas folhas foram encontrados tricomas glandulares em Baccharis gaudichaudiana DC. (Budel et al., 2003), Baccharis sagittalis (Less.) DC., Baccharis triangulares Hauman (Petenatti et al., 2007) e Baccharis dracunculifolia DC. (Pegorini et al., 2008).

Tendo em vista a carência de estudos sobre a espécie Baccharis tridentata, objetivou-se neste trabalho avaliar a composição química do óleo essencial, atividade antioxidante, fungitóxica e estudar as estruturas nas quais o óleo essencial é armazenado na superfície foliar por meio de microscopia eletrônica de varredura (MEV).

\section{MATERIAL E MÉTODO}

\section{Material vegetal}

As folhas de Baccharis tridentata foram coletadas em outubro de 2007 , no período da manhã (7:00 horas), com temperatura de $20^{\circ} \mathrm{C}$, no município de Itumirim-MG/Brasil. A identificação taxonômica da espécie em estudo foi realizada pelo professor Manoel Lousada Gavilanes, do Departamento de Biologia da UFLA (Universidade Federal de Lavras), e uma exsicata da espécie encontra-se registrada no Herbário ESAL (Escola Superior de Agricultura de
Lavras), com o número de registro 5.488 .

Para a extração do óleo essencial empregouse a técnica de hidrodestilação, utilizando-se o aparelho de Clevenger modificado adaptado a um balão de fundo redondo com capacidade de 4 litros (Guimarães et al., 2008). O processo de extração foi realizado no período de 2 horas, mantendo a água em ebulição. Em seguida, coletou-se o hidrolato, que foi levado a centrífuga de cruzeta horizontal, sem refrigeração, a 965,36 $g$ por 5 minutos. O óleo essencial foi retirado com o auxílio de pipeta de Pasteur e acondicionado em frasco de vidro envolto por papel alumínio.

Paralelamente às extrações, realizou-se o teste de umidade, de acordo com o método oficial da AOCS (American Oil Chemists' Society), adaptado por Pimentel et al. (2006). O rendimento do óleo essencial foi calculado e expresso em peso de óleo por peso de folhas com base livre de umidade (\% p/p BLU).

\section{Caracterização química e quantificação dos constituintes do óleo essencial}

A análise qualitativa do óleo essencial foi realizada por cromatografia em fase gasosa acoplada à espectrometria de massas (CG/EM), utilizando-se o aparelho Shimadzu CG-17A com detector seletivo de massa modelo QP 5000 sob as seguintes condições experimentais: coluna capilar; sílica fundida (30 m x 0,25 mm) com fase ligada DB5 $(0,25 \mu \mathrm{m}$ de espessura de filme); temperatura do injetor: $220^{\circ} \mathrm{C}$; programação da coluna: temperatura inicial de $60^{\circ} \mathrm{C}$, sendo acrescidos $3^{\circ} \mathrm{C}$ a cada minuto até atingir $240^{\circ} \mathrm{C}$; gás carreador hélio (1 $\left.\mathrm{mL} \mathrm{min}^{-1}\right)$; taxa de split: 1:10; volume injetado $1 \mu \mathrm{L}$ (1\% de solução em diclorometano) e pressão inicial na coluna de 100,2 $\mathrm{KPa}$. As condições de EM foram energia de impacto: $70 \mathrm{eV}$; velocidade de decomposição: 1000; intervalo de decomposição: 0.50; e fragmentos de 45 Daltons a 450 Daltons decompostos. Injetou-se, nas mesmas condições das amostras, uma mistura de hidrocarbonetos $\left(\mathrm{C}_{9} \mathrm{H}_{20} ; \mathrm{C}_{10} \mathrm{H}_{22} ; \mathrm{C}_{11} \mathrm{H}_{24} ; \ldots \mathrm{C}_{24} \mathrm{H}_{50}\right.$; $\mathrm{C}_{25} \mathrm{H}_{52} ; \mathrm{C}_{26} \mathrm{H}_{54}$ ). Os espectros obtidos foram comparados com o banco de dados da biblioteca Wiley 229 e os índices de Kovats calculados para cada constituinte, foram comparados com os tabelados, de acordo com Adams (2007).

A análise quantitativa foi realizada por cromatografia em fase gasosa com detector de ionização de chamas (FID), utilizando-se um aparelho Shimadzu CG - 17A, realizada nas seguintes condições experimentais: coluna capilar (DB5) constituída 5-fenilmetilpolisiloxano, temperatura do injetor $220^{\circ} \mathrm{C}$; temperatura do FID $250^{\circ} \mathrm{C}$; programação da coluna: temperatura inicial de $60^{\circ} \mathrm{C}$, sendo acrescidos $3^{\circ} \mathrm{C}$ a cada minuto até atingir $240^{\circ} \mathrm{C}$. Utilizou-se como gás de arraste o nitrogênio $\left(0,95 \mathrm{~mL} \mathrm{~min}^{-1}\right)$ e a razão de separação de 1:20. O volume injetado de amostra foi 
$1 \mu \mathrm{L}$ diluído na razão de 1:100 (v/v) em diclorometano, sendo a quantificação de cada constituinte obtida por meio de normalização de áreas (\%).

\section{Análise das glândulas secretoras por microscopia eletrônica de varredura \\ As análises foram realizadas no Laboratório} de Microscopia Eletrônica e Análise Ultra-estrutural (LME), do Departamento de Fitopatologia da UFLA. Para realização destas, foram utilizadas folhas adultas, posteriormente lavadas em água corrente e cortadas em pedaços de aproximadamente $0,5 \mathrm{~cm}$ de largura. O material foi imerso em solução fixativa Karnovisky, $\mathrm{pH}$ 7,2 por período de 24 horas para a fixação do mesmo. Após, foram lavados três vezes (10 minutos cada lavagem) em tampão cacodilato 0,05 M. Em seguida as secções foram transferidas para uma solução de tetróxido de ósmio/água $(1,0 \%)$ por 1 hora; posteriormente o material foi lavado em água destilada por três vezes e desidratado em uma série de soluções de acetona (25, 50, 75, 90 e 100\%). Após a desidratação, as amostras foram levadas para o aparelho de ponto crítico Balzers CPD 030 para substituição da acetona por $\mathrm{CO}_{2}$ e complementação da secagem. Os espécimes obtidos foram montados em suportes de alumínio "stubs" com fita de carbono sobre uma película de papel alumínio e cobertos com ouro no evaporador Balzers SCD 050, e posteriormente foram observados em microscópio eletrônico de varredura LEO EVO 40 (Combrinck et al., 2007).

\section{Atividade antioxidante}

A atividade antioxidante foi avaliada perante o consumo do radical estável DPPH e a oxidação do sistema $\beta$-caroteno/ácido linoleico. Os compostos antioxidantes, timol (Acrõs - 99\%) e $\alpha$-tocoferol (Acrõs - 99\%) foram utilizados como referência. Cada ensaio foi realizado três vezes sendo calculada a média dos resultados e os desvios padrões.

Determinação da atividade antioxidante por meio do método de sequestro de radicais livres DPPH (2,2-difenil-1-picrilhidrazil)

A avaliação da atividade antioxidante diante do consumo de DPPH foi realizada de acordo com a metodologia desenvolvida por Ayscough \& Russel (1965) seguida por modificações. Foi preparada uma solução em metanol de DPPH na concentração de $40 \mu \mathrm{g} \mathrm{mL}^{-1}$, a qual foi mantida sob refrigeração e ao abrigo da luz. Paralelamente, foram preparadas soluções metanólicas do óleo essencial e dos compostos antioxidantes utilizados como referência (timol e $\alpha$-tocoferol), ambas na concentração de 500 $\mu \mathrm{g} \mathrm{mL} \mathrm{m}^{-1}$. As misturas reacionais foram preparadas em tubos de ensaio, adicionando-se $0,3 \mathrm{~mL}$ das soluções das amostras a 2,7 mL da solução de DPPH em metanol $\left(40 \mu \mathrm{g} \mathrm{mL}^{-1}\right)$. Em seguida, as leituras de absorbância foram realizadas em espectrofotômetro (Shimadzu UV-160 1PC) a $517 \mathrm{~nm}$, no tempo 0 e 30 min após junção das duas soluções. A porcentagem da atividade antioxidante foi calculada de acordo com a equação [1-( $\left.\left.\mathrm{A}_{\text {amostra }} / \mathrm{A}_{\text {controle }}\right)\right] \times 100$, onde $\mathrm{A}_{\text {amostra }}$ é a absorbância da solução contendo todos os reagentes e $A_{\text {controle }}$ é a absorbância da solução controle (solução contendo todos os reagentes menos os compostos avaliados). Como branco foi utilizada a mistura de $2,7 \mathrm{~mL}$ de metanol e a solução metanólica dos compostos avaliados.

Determinação da atividade antioxidante utilizando o sistema $\beta$-caroteno/ácido linoleico

$A$ avaliação da atividade antioxidante utilizando o ensaio do $\beta$-caroteno/ácido linoleico foi realizada de acordo com as metodologias apresentadas por Kulisic et al. (2004) e Lopes-Lutz et al. (2008) com pequenas modificações. Foi preparada uma solução de $\beta$-caroteno em clorofórmio (0,3 $\left.\mu \mathrm{g} \mathrm{mL}^{-1}\right)$; em seguida, foram adicionados a esta $60 \mu \mathrm{L}$ de ácido linoleico, $600 \mathrm{mg}$ de Tween $20 \AA$ e 1,5 $\mathrm{mL}$ de clorofórmio, sendo o clorofórmio evaporado em rotaevaporador a vácuo (Bücher Rotavapor R 114).

Posteriormente, $175 \mathrm{~mL}$ de água destilada saturada com oxigênio foram acrescidos na mistura sob agitação constante (emulsão A). Em seguida, $2,5 \mathrm{~mL}$ da emulsão $A$ foram adicionados em tubos de ensaio e sob ela foram acrescidos $200 \mu \mathrm{L}$ das soluções metanólicas do óleo essencial e dos compostos antioxidantes utilizados como referência, na concentração de $500 \mu \mathrm{g} \mathrm{mL}^{-1}$. Paralelamente, prepararam-se duas soluções, uma sem o antioxidante (controle) e outra com os mesmos reagentes de A, sem o $\beta$-caroteno (emulsão B - branco).

As leituras das amostras foram realizadas nos tempos 0 e 3 horas após adicionado o antioxidante sobre a emulsão A em espectrofotômetro Shimadzu UV-1601PC utilizando um comprimento de onda de $470 \mathrm{~nm}$. A porcentagem de inibição (porcentagem de atividade antioxidante $A A \%)$ foi calculada por meio da fórmula $A A \%=100 \times\left[1-\left(A_{0}-A_{A} / A_{00}-A_{0 t}\right)\right]$, sendo $A_{0}$ a absorbância no tempo $0 ; A_{t}$ absorbância da mesma solução após 3 horas de incubação; $A_{00}$ a absorbância no tempo 0 da solução contendo $2,5 \mathrm{~mL}$ da emulsão A e $200 \mu \mathrm{L}$ de metanol e $\mathrm{A}_{\text {ot }}$ a absorbância desta solução após 3 horas de incubação.

\section{Atividade fungitóxica}

As culturas dos fungos foram obtidas da micoteca do Departamento de Fitopatologia e identificadas como Fusarium oxysporum CML № 1450, Colletotrichum gloeosporioides CML oo 1449 e Rhizoctonia solani CML № 1448. O método utilizado foi o bioanalítico in vitro de acordo com Nakahara et al. (2003) seguido por modificações, por meio do qual avaliou-se o efeito do óleo essencial de Baccharis 
tridentata Vahl., em diferentes concentrações sobre o crescimento e/ou inibição micelial das culturas fúngicas. As concentrações utilizadas do óleo essencial foram de 50, 100, 150, 200, 500, 1000, 1500 $\mathrm{mg} \mathrm{L}^{-1}$ ( relações massa de óleo essencial por volume de meio de cultura) para todos os fitopatógenos. Para obtenção dessas, inicialmente preparou-se uma solução de óleo essencial em éter etílico, na concentração de $1500 \mathrm{mg} \mathrm{L}^{-1}$, que foi diluída para as concentrações citadas. Posteriormente, acrescentouse $0,25 \mathrm{~mL}$ de cada solução em $24,75 \mathrm{~mL}$ de meio de cultura (BDA) previamente autoclavado e semifundente, resultando em $25 \mathrm{~mL}$ de meio de cultura contendo óleo essencial nas concentrações utilizadas.

O meio de cultura foi vertido em placas de Petri ( $9 \mathrm{~cm}$ de diâmetro) com a posterior inoculação dos fitopatógenos. Foi preparado um controle com o meio de cultura puro (testemunha absoluta) e outro com apenas éter etílico (testemunha relativa) para determinar o efeito desse composto sobre os fitopatógenos.

Para a inoculação dos fitopatógenos, um disco de $9 \mathrm{~mm}$ de diâmetro contendo o micélio de cada fungo (retirado da colônia com doze dias em BDA) foi repicado para o centro da placa, as quais foram vedadas com filme plástico e colocadas em incubadora com "biological oxygen demand" (BOD) a 25ㄷ para os fitopatógenos Fusarium oxysporum e Colletotrichum gloeosporioides e a $21^{\circ} \mathrm{C}$ para Rhizoctonia solani e fotoperíodo de 12 horas. As medidas do crescimento micelial das culturas de Fusarium oxysporume Colletotrichum gloeosporioides foram realizadas no décimo dia após a inoculação dos fungos, e no terceiro dia para Rhizoctonia solani. Para tal, foram traçadas duas retas pela placa de Petri passando pelo centro do disco de $9 \mathrm{~mm}$; uma perpendicular a outra; as leituras foram realizadas pela medição do diâmetro de crescimento das colônias (médias de duas medidas diametralmente opostas) (Balbi-Peña et al., 2006). A porcentagem de inibição do crescimento micelial foi calculada para cada dosagem em relação à testemunha absoluta.

O delineamento experimental para os ensaios biológicos foi inteiramente casualizado, com três repetições. Realizou-se a análise de regressão para avaliar a porcentagem de inibição do crescimento micelial dos fitopatógenos frente às diferentes concentrações do óleo essencial estudado. As análises foram realizadas utilizando-se o programa estatístico SISVAR (Ferreira, 2000).

\section{RESULTADO E DISCUSSÃO}

As folhas frescas de Baccharis tridentata apresentaram um teor de óleo essencial de 0,091\% $\mathrm{p} / \mathrm{p}(\mathrm{BLU})$.

Estudando os teores de óleo essencial apresentados por doze espécies de Baccharis coletadas no Sul do Brasil, Agostini et al. (2005) encontraram teores variáveis entre 0,1 e $0,5 \% \mathrm{p} / \mathrm{v}$, sendo que, seis espécies apresentaram teor de $0,1 \%$. Os teores encontrados por Silva et al. (2007) para plantas de Baccharis trimera cultivadas e selvagens variaram de 0,11 a $0,32 \% \mathrm{p} / \mathrm{v}$ de acordo com a época de colheita. Silva et al. (2006), estudando plantas de Baccharis trimera submetidas a diferentes níveis de radiação luminosa, encontraram teores de óleo essencial variando de 0,036 a 0,059\% p/p. Desta forma observa-se que o teor de óleo essencial apresentado pela espécie de Baccharis estudada está de acordo com os teores de óleo essencial encontrados para outras espécies do mesmo gênero, demonstrando o potencial da mesma como fonte de óleo essencial para diversos estudos.

De acordo com os dados apresentados na Tabela 1, foram identificadas 28 substâncias que são responsáveis por $93,14 \%$ da constituição química do óleo essencial de Baccharis tridentata. $\mathrm{O} \alpha$-tujeno apresentou-se como composto majoritário (22,93\%), seguido pelo $\beta$-pineno (20,33\%) e $\beta$-felandreno $(16,15 \%)$.

Esses resultados não corroboram com aqueles encontrados por Ferracini et al. (1995), que estudando a composição química de várias espécies pertencentes ao gênero Baccharis, encontraram o espatulenol (21,20\%, constituinte majoritário), seguido pelo $\delta$-cadineno $(7,68 \%)$ e pelo globulol $(5,86 \%)$, como constituintes principais do óleo essencial de Baccharis tridentata, coletada em Santana do Riacho/ MG. No entanto, a presença do monoterpeno $\beta$-pineno $(20,33 \%)$ como constituinte majoritário está de acordo com os resultados apresentados por Agostini et al. (2005), que avaliando a composição química de várias espécies de Baccharis nativas do Rio Grande do Sul e coletadas em diferentes localidades do estado, também encontraram $\beta$-pineno como constituinte majoritário de $B$. articulata $(41,4 \%$ a $52,8 \%)$ e de $B$. cogata $(27,2 \%)$.

A composição química dos óleos essenciais de espécies de Baccharis é muito variada. Silva et al. (2007) estudando a variabilidade sazonal dos óleos essenciais de Baccharis trimera selvagem e cultivada, encontraram como constituintes majoritários o $(\mathrm{E})$ cariofileno com seu teor variando de 12 a $21 \%$, o germacreno-D com teor entre 6,3 e $28 \%$ e o biciclogermacreno com teor entre 12 e 23\%. Schossler et al. (2009) encontraram os compostos biciclogermacreno $(9,73 \%)$ e o cis-cadin-4-en-7-ol $(6,77 \%)$ como constituintes majoritários do óleo essencial de Baccharis punctulata e o (E)-nerolidol $(22,80 \%)$ mais o $\beta$-pineno $(12,17 \%)$ como constituintes majoritários do óleo essencial de Baccharis dracunculifolia. Já Parreira et al. (2010) encontraram o (E)-nerolidol (33,51\%) e o espatulenol (16,24\%) como constituintes majoritários do óleo essencial de

Rev. Bras. PI. Med., Botucatu, v.13, n.4, p.456-466, 2011. 
TABELA1. Constituintes do óleo essencial de Baccharis tridentata Vahl. identificados por CG/EM e os respectivos teores.

\begin{tabular}{|c|c|c|}
\hline Composto & $\begin{array}{c}\text { IK } \\
\text { calculado }\end{array}$ & $\begin{array}{l}\text { Teor } \\
(\%)\end{array}$ \\
\hline$\alpha$ - tujeno & 927 & 22,93 \\
\hline$\alpha$ - pineno & 934 & 0,60 \\
\hline$\beta$-pineno & 975 & 20,33 \\
\hline Mirceno & 991 & 6,08 \\
\hline$\delta$-3- careno & 1015 & 0,25 \\
\hline$\rho$-cimeno & 1024 & 0,19 \\
\hline Limoneno & 1028 & 1,30 \\
\hline$\beta$-felandreno & 1029 & 16,15 \\
\hline (E)- $\beta$-ocimeno & 1050 & 3,42 \\
\hline Y- terpineno & 1061 & 2,33 \\
\hline Terpinoleno & 1088 & 0,73 \\
\hline Fenchol & 1116 & 0,14 \\
\hline 4- terpineol & 1180 & 3,53 \\
\hline$\alpha$-terpineol & 1188 & 0,54 \\
\hline Acetato de bornila & 1283 & 0,12 \\
\hline$\beta$-borboneno & 1379 & 0,09 \\
\hline$\beta$-elemeno & 1388 & 0,26 \\
\hline (E)-cariofileno & 1414 & 4,24 \\
\hline$\alpha$-humuleno & 1448 & 0,28 \\
\hline Germacreno-D & 1477 & 4,44 \\
\hline Biciclogermacreno & 1491 & 0,19 \\
\hline$\alpha$-muuroleno & 1500 & 1,58 \\
\hline Y-cadineno & 1513 & 0,34 \\
\hline$\delta$-cadineno & 1520 & 0,81 \\
\hline Espatulenol & 1576 & 0,19 \\
\hline Oxido cariofileno & 1579 & 0,87 \\
\hline Epi- $\alpha$ - cadinol & 1642 & 1,00 \\
\hline$\alpha$-cadinol & 1658 & 0,21 \\
\hline Hidrocarbonetos monoterpênicos & & 74,31 \\
\hline Monoterpenos oxigenados & & 4,33 \\
\hline Hidrocarbonetos sesquiterpênicos & & 12,27 \\
\hline Sesquiterpenos oxigenados & & 2,27 \\
\hline Total & & 93,14 \\
\hline
\end{tabular}

Baccharis dracunculifolia. Boix et al. (2010) encontraram os compostos verbenona (10,1\%), mirceno (10,2\%), 1,8cineol $(10,4 \%)$ e a cânfora $(25,2 \%)$ como constituintes principais do óleo essencial de Baccharis dracunculifolia.

Muitos trabalhos relatam a predominância de compostos monoterpênicos e sesquiterpênicos na composição química dos óleos essenciais pertencentes a plantas do gênero Baccharis. $\mathrm{Na}$ Tabela 1 observa-se que $78,64 \%$ da composição química do óleo essencial estudado é representada por monoterpenos e $14,54 \%$ de sesquiterpenos, este resultado encontra-se de acordo com os resultados 
encontrados por Boix et al. (2010) para o óleo essencial de Baccharis dracunculifolia, que encontraram $78,50 \%$ de monoterpenos e $21,40 \%$ de sesquiterpenos. Por outro lado, estes resultados contrariam vários trabalhos que demonstram os sesquiterpenos como os compostos predominantes nos óleos essenciais deste gênero de plantas, como os de Lago et al. (2008), que estudaram a composição química dos ramos floridos de Baccharis trimera (Less.) DC. e encontraram uma predominância de sesquiterpenos, 48,5e 68,6\% no óleo essencial das espécimes feminina e masculina, respectivamente; e os de Schossler et al. (2009), que estudando a composição química dos óleos essenciais de Baccharis punctulata e Baccharis dracunculifolia encontraram 54,76 e $45,87 \%$ de sesquiterpenos em seus óleos essenciais extraídos por hidrodestilação.

Todas estas variações podem ser atribuídas a fatores como sazonalidade, ritmo circadiano, desenvolvimento, temperatura, disponibilidade hídrica, nutrientes entre outros (Gobbo Neto \& Lopes, 2007). Silva et al. (2007) demonstraram a influência da variação sazonal na composição química do óleo essencial em populações de Baccharis trimera natural e cultivada, encontrando a presença de três tipos de substâncias diferentes em relação à origem e a fase de desenvolvimento das plantas.

Pelas imagens de microscopia eletrônica de varredura (Figura 1) foi possível visualizar as estruturas secretoras de óleos essenciais, classificadas como tricomas glandulares do tipo peltado. Estes estão situados na superfície foliar abaxial e adaxial desta espécie, sendo encontrados isolados ou agrupados, observando em ambas as faces baixa densidade dos mesmos, bem como a ausência de pelos e grande quantidade de ceras situadas nas superfícies abaxial e adaxial.

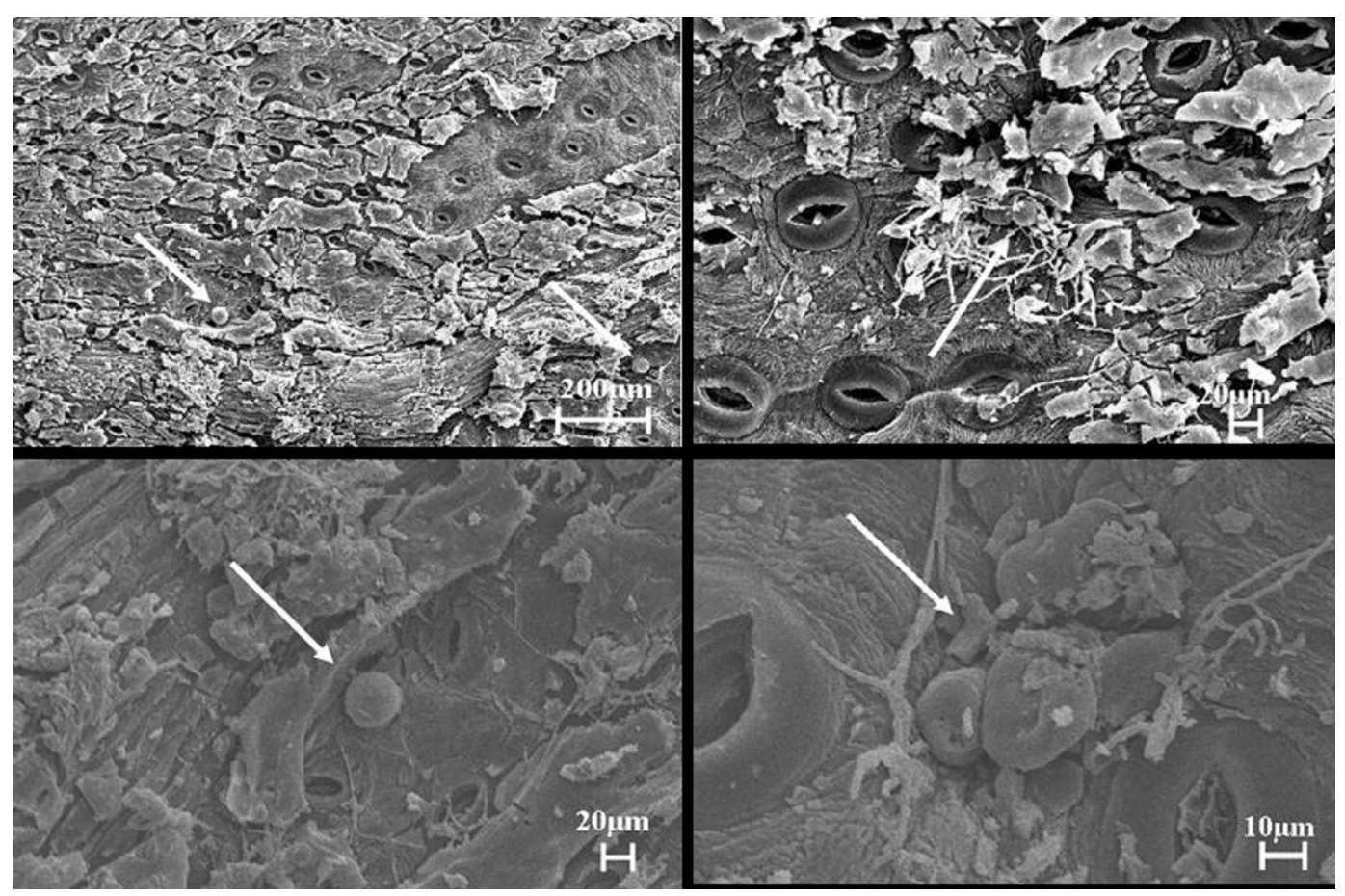

FIGURA 1. Micrografia eletrônica de varredura (MEV) da epiderme na face foliar de Baccharis tridentata (as setas indicam a presença de tricomas).

A presença de tricomas glandulares na superfície foliar de plantas do gênero Baccharis já foi relatada, uma vez que, já foram observados tricomas glandulares pluricelulares, com posição apical arredondada, reunidos pela base em tufos e localizados em pequenas depressões nas superfícies foliares de Baccharis dracunculifolia (Budel et al., 2004 a). Molares et al. (2009) também observaram a presença de tricomas agrupados em plantas de Baccharis abovata Hook. Budel \& Duarte (2007) encontraram tricomas glandulares inseridos em pequenas depressões nas folhas de Baccharis coridifolia. Diante destes estudos, pode se afirmar que, os resultados encontrados neste trabalho corroboram com aqueles já citados na literatura para espécies pertencentes ao gênero Baccharis.

Muitas pesquisas têm sido desenvolvidas com o objetivo de caracterizar as estruturas secretoras de óleos essenciais, em diversas espécies de plantas pertencentes a várias famílias e gêneros. A presença de tricomas glandulares nas superfícies foliares de Salvia blepharophyll (Lamiaceae) foi observada como 
sítios de produção e armazenamento de óleos essenciais (Bisio et al., 1999). Trabalhos de Combrinck et al. (2007) sobre a morfologia dos tricomas glandulares presentes nesta mesma espécie vegetal, demonstraram a presença de tricomas peltados de dois tamanhos diferentes, sendo um maior (com aproximadamente $50 \mu \mathrm{m}$ de diâmetro) e outro menor (com $20 \mu$ m de diâmetro).

Os resultados da avaliação antioxidante do óleo essencial de Baccharis tridentata pelo teste de neutralização do radical DPPH e pela inibição da oxidação do sistema acoplado $\beta$-caroteno/ácido linoleico estão apresentados na Figura 2. Observase que o óleo essencial apresentou uma atividade antioxidante próxima a zero para ambos os testes, já os padrões, timol e $\alpha$-tocoferol foram os que apresentaram as maiores atividades, havendo um destaque por parte do $\alpha$-tocoferol.

Estes resultados estão de acordo com trabalhos sobre a atividade antioxidante de óleos essenciais de várias espécies de Artemisia pelos mesmos métodos, os quais também não observaram atividade antioxidante considerável para os óleos essenciais estudados (Lopes-Lutz et al., 2008). Entretanto em outros trabalhos realizados com a mesma metodologia foram encontrados valores que caracterizam a atividade antioxidante para o óleo essencial de Petroselinum crispum (Zhang et al., 2006). Estudos sobre o potencial antioxidante dos óleos essenciais de Pimpinella anesetume Pimpinella flabellifolia demonstraram atividade antioxidade significativamente maior para os óleos essenciais estudados pelo ensaio do DPPH em relação ao padrão utilizado (ácido ascórbico) (Tepe et al., 2006). A atividade antioxidante dos óleos essenciais de Satureja spicigera e Satureia cuneifolia foi superior a dos antioxidantes utilizados pela indústria como o $\mathrm{BHT}$ e o ácido ascórbico pelo ensaio utilizando o $\mathrm{DPPH}$, no entanto, perante o ensaio da oxidação do $\beta$-caroteno/ácido linoleico estes óleos essenciais apresentaram atividades antioxidantes inferiores a apresentada por estes compostos (Eminagaoglu et al., 2007).

A atividade fungitóxica do óleo essencial das folhas de Baccharis tridentata sobre o crescimento micelial dos fitopatógenos Colletotrichum gloeosporioides, Fusarium oxysporium e Rhizoctonia solani pode ser observada nas Figuras 3, 4 e 5, respectivamente.

Pelos dados obtidos observou-se que houve inibição considerável do crescimento micelial frente à presença do óleo essencial para Fusarium oxysporium, Rhizoctonia solani, sendo mais eficiente para o Rhizoctonia solani, o qual teve $72,28 \%$ do crescimento micelial impedido com a concentração de $1000 \mathrm{mg} \mathrm{L}^{-1}$ do óleo essencial. Sobre o crescimento micelial do fitopatógeno Colletotrichum gloeosporioides, o óleo essencial não apresentou atividade inibitória significativa. De acordo com as análises de regressão realizadas com a finalidade de demonstrar o comportamento da inibição do crescimento micelial dos fitopatógenos estudados, em relação às concentrações de óleo essencial utilizadas, observa-se que no intervalo das concentrações estudadas a inibição do crescimento micelial dos fungos Colletotrichum gloeosporioidese Rhizoctonia solaniaumenta de acordo com o aumento da concentração do óleo essencial, seguindo a equação de primeiro grau, o que não acontece em relação a inibição do crescimento micelial do fungo Fusarium oxysporium, uma vez que, sobre este esta relação segue equação de segundo grau.

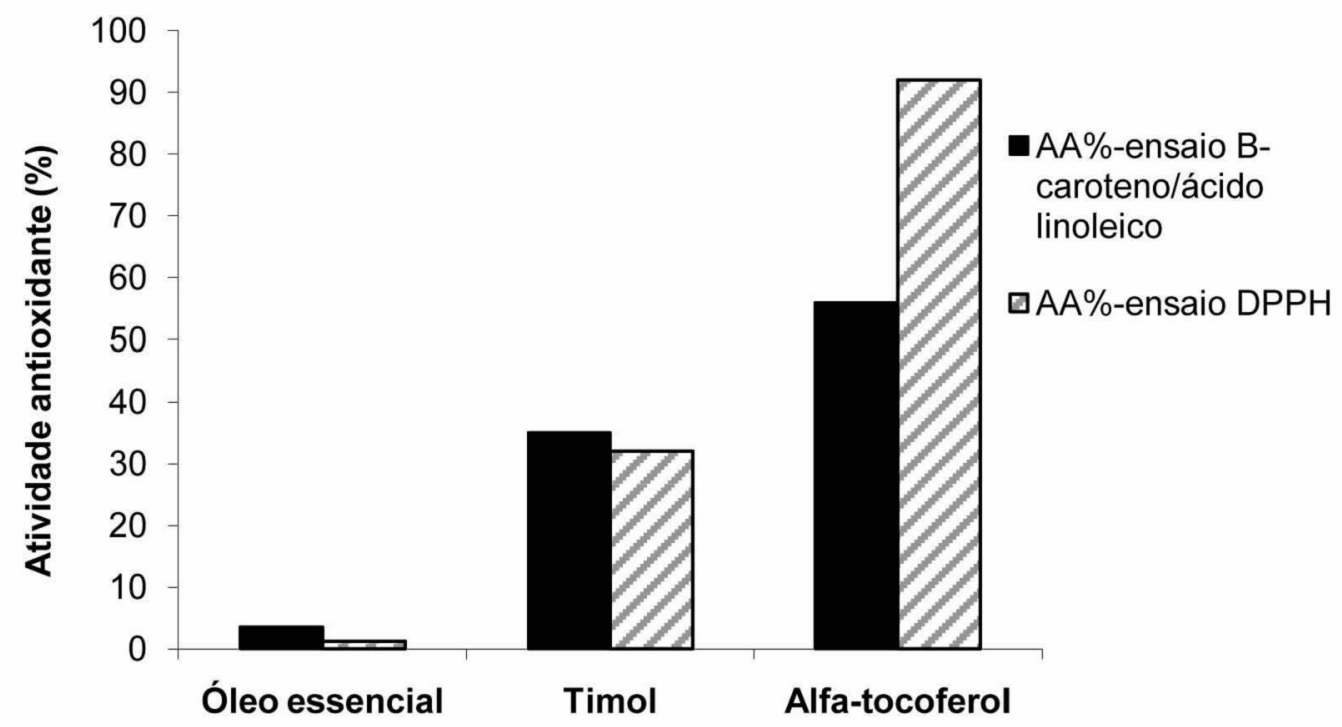

FIGURA 2. Atividade antioxidante do óleo essencial de Baccharis tridentata, do timol e do $\alpha$-tocoferol diante dos ensaios do DPPH e do sistema $\beta$-caroteno/ácido linoleico. 


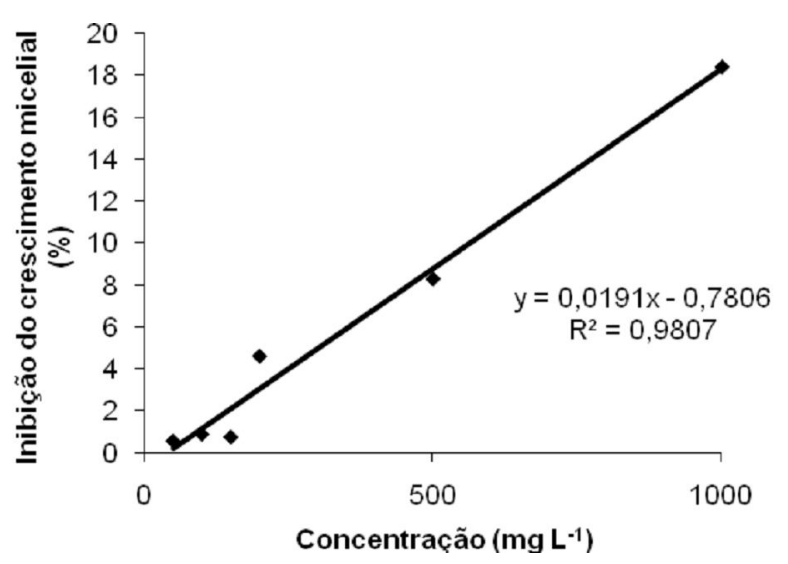

FIGURA 3. Inibição do crescimento micelial do fitopatógeno Colletotrichum gloeosporioides causado pelo óleo essencial de Baccharis tridentata.

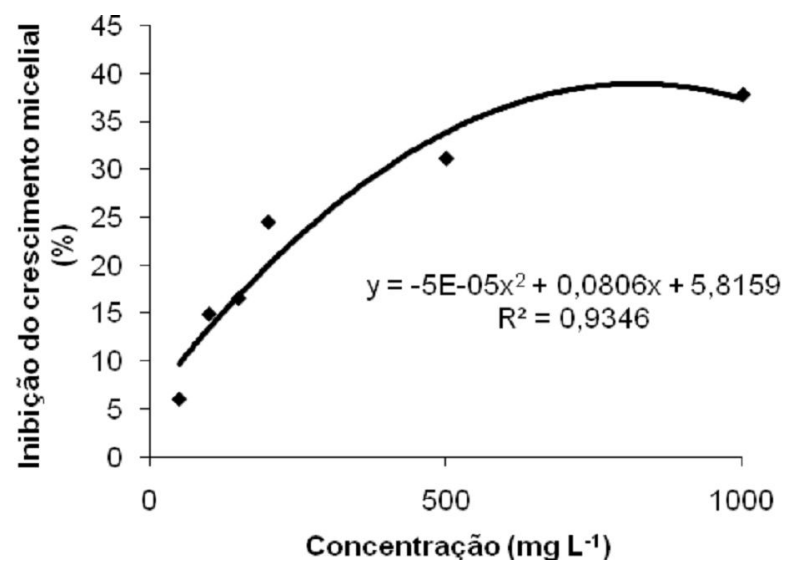

FIGURA 4. Inibição do crescimento micelial do fitopatógeno Fusarium oxysporium causado pelo óleo essencial de Baccharis tridentata.

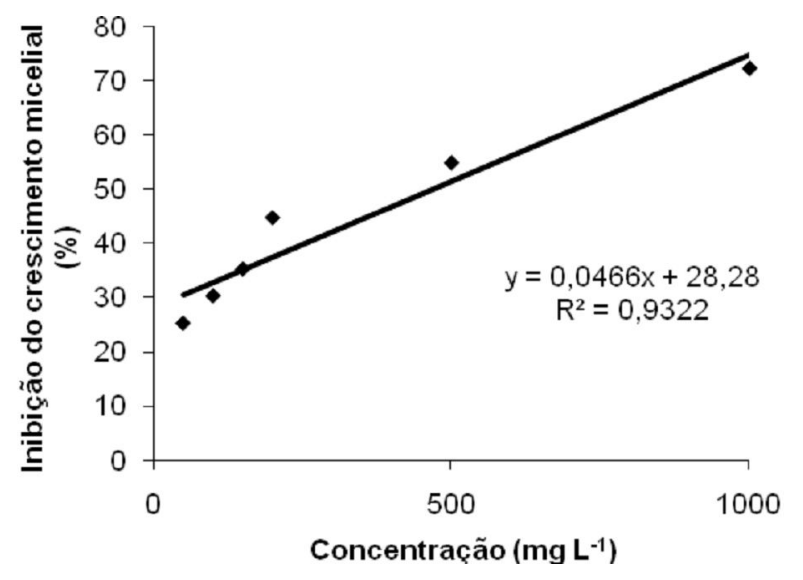

FIGURA 5. Inibição do crescimento micelial do fitopatógeno Rhizoctonia solani causado pelo óleo essencial de Baccharis tridentata.
A atividade fungitóxica encontrada para o óleo essencial de Baccharis tridentata está de acordo com as atividades apresentadas por diversos óleos essenciais. Salgado et al. (2003) demonstraram o efeito fungicida (capaz de causar a morte dos fitopatógenos) dos óleos essenciais de três espécies de eucalipto (Eucalyptus urophylla, Eucalyptus citriodora e Eucalyptus camaldulensis) sobre os fitopatógenos (Fusarium oxysporum, Botrytis cinerea e Bipolaris sorokiniana). Outros estudos realizados por Guimarães et al., (2011), constataram que a atividade fungitóxica do óleo essencial de Cymbopogon citratus e dos componentes majoritários mirceno e citral (mistura isomérica de geranial e neral) sobre os fungos fitopatogênicos Fusarium oxysporum, Colletotrichum gloeosporioides e Rhizoctonia solani, foi exercida pelo citral.

Vários trabalhos comprovam a presença do trans-cariofileno como antimicrobiano, principalmente em fungos patogênicos e bactérias Gram (+/-) (Couladis et al., 2000; Novak et al., 2001). O composto germacreno-D foi encontrado em Artemisia parviflora (Rana et al., 2003), Piper friedrichsthallie $P$. pseudollindeni (Vila et al., 2003), e em Jupinerus turbinata (Consentino et al., 2003) e Lippia javanica (Ngassapa et al., 2003) apresentando atividade bactericida e fungicida.

A análise por CG/EM do óleo de Leonurus sibiricus, revelou a presença de 13 compostos, sendo que dentre os identificados pode-se observar a predominância dos sesquiterpenos trans-cariofileno (33,43\%), alfa-humuleno $(21,49 \%)$ e germacreno-D (24,95\%), responsáveis por $70 \%$ da composição do óleo. Os autores afirmam que essas substâncias apresentam esqueletos carbônicos com ampla atividade antibacteriana, antifúngica e inibidores enzimáticos (Almeida et al., 2005).

Diante dos dados obtidos, confirma-se que o óleo essencial de Baccharis tridentada é constituído por monoterpenos e sesquiterpenos, corroborando com estudos realizados com óleos essenciais de outras espécies de Baccharis, os quais são constituídos predominantemente por compostos pertencentes a estas classes. Observou-se a inexistência de atividade antioxidante do mesmo perante as metodologias estudadas, descartando a possível utilização como antioxidante, tanto na saúde, como na conservação de alimentos. Já a atividade fungitóxica encontra-se de acordo com a atividade apresentada por óleos essenciais de outras plantas, demonstrando que o mesmo pode vir a ser utilizado para o controle de fungos na agricultura e em frutos no período de pós-colheita. Em relação às estruturas secretoras estas se apresentaram semelhantes às estruturas encontradas em outras espécies do gênero Baccharis. 


\section{AGRADECIMENTO}

Ao Laboratório de Microscopia Eletrônica e Análise Ultra-Estrutural (LME) do Departamento de Fitopatologia da Universidade Federal de Lavras - LavrasMG pelas análises microscópicas, ao Laboratório de Análises e Síntese de Agroquímicos do Departamento de Química da Universidade Federal de Viçosa (UFV) Viçosa-MG pelas análises qualitativas do óleo essencial, ao Conselho Nacional de Desenvolvimento Científico e Tecnológico (CNPq), à Fundação de Amparo à Pesquisa de Minas Gerais (Fapemig) pelos recursos financeiros e concessão de bolsas.

\section{REFERÊNCIA}

ADAMS, R.P. Identification of essential oils components by gas chromatography/ mass spectroscopy. 4.ed. Carol Stream: Allured, 2007.469p.

AGOSTINI, F. et al. Estudo do óleo essencial de algumas espécies do gênero Baccharis (Asteraceae) do Sul do Brasil. Revista Brasileira de Farmacognosia, v.15, n.3, p.215-9, 2005.

ALMEIDA, L.F.R.; DELACHIAVE, M.E.A.; MARQUES, M.O.M. Composição do óleo essencial de rubim (Leonurus sibiricus L. - Lamiaceae). Revista Brasileira de Plantas Medicinais, v.8, n.1, p.35-8, 2005.

AVANCINI, C.A.M.; WIEST, J.M.; MUNDSTOCK, E. Bacteriostatic and bactericidal activity of the Baccharis trimera (Less.) DC. - Compositae decocto, as disinfectant or antisseptic. Arquivo Brasileiro de Medicina Veterinária e Zootecnia, v.52, n.3, p.230-4, 2000. AYSCOUGH, P.B.; RUSSELL, K.E. Spectroscopic studies of the reversible reaction between 2,2-Diphenyl-1picrylhydrazyl and 2,4,6-tri-t-butylphenol. Canadian Journal of Chemistry, v.43, p.3039-44, 1965.

BAJPAI, V.K.; RAHMAN, A.; KANG, S.C. Chemical composition and anti-fungal properties of the essential oil and crude extracts of Metasequoia glyptostroboides Miki ex Hu. Industrial Crops and Products, v.26, n.1, p.2835, 2007.

BALBI-PEÑA, M.I. et al. Controle de Alternaria solani em tomateiro por extratos de Curcuma longa e curcumina I. Avaliação in vitro. Fitopatologia Brasileira, v.31, n.3, p.310-4, 2006.

BARROSO, G.B. Sistemática de angiospermas do Brasil. 3.ed.Viçosa: Imprensa Universitária da Universidade Federal de Viçosa,1986. 326p.

BISIO, A. et al. Glandular hairs and secretede material in Salvia blepharophylla Brandegee ex Epling grown in Italy. Annals of Botany, v.83, n.4, p.441-52, 1999.

BOIX, Y.F. et al. Volatile compounds from Rosmarinus officinalis L. and Baccharis dracunculifolia DC. growing in southeast coast of Brazil. Química Nova, v.33, n.2, p.255-7, 2010.

BOTTERWECK, A.A.M. et al. Intake of butilated hydroxyanisole and butilated hydroxytoluene and stomach cancer risk: results from analyses in the Netherlands cohort study. Food Chemistry and Toxicology, v.38, n.7, p.599-605, 2000.

BUDEL, J.M.; DUARTE, M.R.; SANTOS, C.A.M. Caracteres morfo-anatômicos de Baccharis gaudichaudiana DC.,
Asteraceae. Latin American Journal of Pharmacy, v.22, n.4, p.313-20, 2003.

BUDEL, J.M. et al. Morfoanatomia foliar e caulinar de Baccharis dracunculifolia DC., Asteraceae. Acta Farmaceutica Bonaerense, v.23, n.4, p.477-83, 2004a. BUDEL, J.M.; DUARTE, M.R.; SANTOS, C.A.M. Stem morpho-anatomy of Baccharis cylindrical (Less.) DC. (Asteraceae). Revista Brasileira de Ciências Farmacêuticas, v.40, n.1, p.93-9, 2004b.

BUDEL, J.M.; DUARTE, M.R. Caracteres morfoanatômicos de partes vegetativas aéreas de Baccharis coridifolia DC. (Asteraceae-Astereae). Latin American Journal of Pharmacy, v.26, n.5, p.723-31, 2007.

COMBRINCK, S. et al. Morphology and histochemistry of the glandular trichomes of Lippia scaberrinma (Verbenaceae). Annals of Botany, v.99, p.111-9, 2007.

CONSENTINO, S.; SINGH, Z.; TAN, B.C. Composition and antimicrobial properties of Sardinian Juniperus essential oils against foodborne pathogens and spoilage microorganisms. Journal of Food Protection, v.66, p.1288-91, 2003.

COULADIS, M.; GRUISSEN, W.; JONES, R.L. Essential oil Plhomis lanata growing in Greece: chemical composition and antimicrobial activity. Planta Medica, v.66, p.670-2, 2000.

DIANZ, F. et al. Fungicide resístanse in Botrytis cinerea isolata from strawberry crops in Huelva (southwetern Spain). Phytoparasitica, v.30, p.529-34, 2002.

EBRAHIMABADI, A. et al. Composition and antioxidant and antimicrobial activity of the essential oil and extracts of Stachys inflata Benth from Iran. Food Chemistry, v.119, n.2, p.452-8, 2010.

EMINAGAOGLU, O. et al. The in vitro antioxidative properties of the essential oils and methanol extracts of Satureja spicigera (K. Koch.) Boiss. and Satureja cuneifolia ten. Food Chemistry, v.100, n.1, p.339-43, 2007. FERRACINI, V.L. et al. Essential oils of seven Brazilian Baccharis species. Journal of Essential Oil Research, v.7, p.355-67, 1995.

FERREIRA, D.F. Análises estatísticas por meio do Sisvar para Windows versão 4.0. In: REUNIÃO ANUAL DA REGIÃO BRASILEIRA DA SOCIEDADE INTERNACIONAL DE BIOMETRIA, 45., 2000, São Carlos. Anais... São Carlos: UFSCar, 2000. p.255-8.

FLORES, R.C. et al. Chemical composition of essential oil of Baccharis salicifolia (Ruiz \& Pavon) Pers. and antibacterial activity. Journal of the Chilean Chemical Society, v.54, n.4, p.475-6, 2009.

GIULIANO, D.A. Classificación infragenérica de las espécies Argentinas de Baccharis (Asteraceae, Astereae). Darwiniana, v.39, n.1-2, p.131-54, 2001.

GOBBO-NETO, L.; LOPES, N.P. Plantas medicinais: fatores de influência no conteúdo de metabólitos secundários. Química Nova, v.30, n.2, p.374-81, 2007. GUIMARÃES, L.G.L. et al. Influência da luz e da temperatura sobre a oxidação do óleo essencial de capim-limão (Cymbopogon citratus (DC.) Stapf). Química Nova, v.31, n.6, p.1476-80, 2008.

GUIMARÃES, L.G.L. et al. Atividades antioxidante e fungitóxica do óleo essencial de capim-limão e do citral. Revista Ciência Agronômica, v.42, n. 2, p.464-72, 2011. HELLWING, F.H. Studies on the trichomes of some Asteraceae (compositae). Flora, v.186, n.5, p.425-44, 1992. 
KORDALI, S.; KOTAN, R.; CAKIR, A. Screening of antifungal activities of 21 oxygenated monoterpenes invitro as plant disease control agents. Allelopathy Journal, v.19, n.2, p.373-91, 2007.

KULISIC, T. et al. Use of different methods for testing antioxidative activity of oregano essential oil. Food Chemistry, v.85, n.4, p.633-40, 2004.

LAGO, J.H.G. et al. Composição química dos óleos essenciais de seis espécies do gênero Baccharis de "Campos de Altitude" da Mata Atlântica Paulista. Quimica Nova, v.31, n.4, p.727-30, 2008.

LEWINSOHN, E. et al. Histochemical localization of citral accumulation in lemongrass leaves (Cymbopogon citratus (DC.) Stapf., Poaceae). Annals of Botany, v.81, n.1, p.35-9, 1998

LOPES-LUTZ, D. et al. Screening of chemical composition, antimicrobial and antioxidant activities of Artemisia essential oils. Phytochemistry, v.69, n.8, p.1732-8, 2008.

MOLARES, S. et al. Etnobotanica, anatomía y caracterizácion físico-química del aceite esencial de Baccharis abovata Hook. Ex Arn. (Asteraceae: Astereae). Acta Botanica Brasilica, v.23, n.2, p.578-89, 2009.

NAKAHARA, K. et al. Chemical composition and antifungal activity of essential oil from Cymbopogon nardus (citronella grass). Japan Agricultural Research Quaterly, v.37, n.4, p.249-52, 2003.

NGASSAPA, O. et al. Composition and antimicrobial activity of essential oils of two populations of Tanzanian Lippia javanica (Burm. f.) Spreng. (Verbenaceae). Flavour and Fragrance Journal, v.18, p.221-4, 2003.

NOVAK, J. et al. Essential oils of different cultivars of Cannabis sativa $\mathrm{L}$. and their antimicrobial activity. Flavour and Fragrance Journal, v.16, p.259-62, 2001.

PARREIRA, N.A. et al. Antiprotozoal, schistosomicidal, and antimicrobial activities of the essential oil from the leaves of Baccharis dracunculifolia. Chemistry \& Biodiversity, v.7, p.993-1001, 2010.

PEGORINI, F.; MARANHO, L.T.; ROCHA, L.D. Organização estrutural das folhas de Baccharis dracunculifolia DC., Asteraceae. Revista Brasileira de Farmácia, v.89, n.3, p.272-5, 2008.

PETENATTI, E.M. et al. Medicamentos herbarios en el centro-oeste Argentino. VI. Caracterización y control de calidad de dos especies de "Carquejas": Baccharis sagittalis y $B$. triangularis (Asteraceae). Latin American Journal of Pharmacy, v.26, p.201-8, 2007.

PIMENTEL, F.A. et al. A convenient method for the determination of moisture in aromatic plants. Química Nova, v.29, n.2, p.373-5, 2006.

RAMALHO, V.C.; JORGE, N. Antioxidantes utilizados em óleos, gorduras e alimentos gordurosos. Química Nova, v.29, n.4, p.755-60, 2006.

RANA, V.S. et al. Essential oil composition of Artemisia parviflora aerial parts. Flavour and Fragrance Journal, v.18, p.342-4, 2003.

RANGEL, D. et al. Actividad antimicrobiana de los extractos etanólico, acetónico y acuoso de Baccharis nitida. Revista de la Facultad de Farmacia, v.42, p.3546, 2001.

SALGADO, A.P.S.P. et al. Avaliação da atividade fungitóxica de óleos essenciais de folhas de Eucalyptus sobre Fusarium oxysporum, Botrytis cinerea e Bipolaris sorokiniana. Ciência e Agrotecnologia, v.27, n.2, p.24954, 2003.

SCHOSSLER, P. et al. Volatile compounds of Baccharis punctulata, Baccharis dracunculifolia and Eupatorium laevigatum obtained using solid phase microextraction and hydrodistillation. Journal of Brazilian Chemical Society, v.20, n.2, p.277-87, 2009.

SILVA, F.G. et al. Influence of radiation level on plant growth, yield and quality of essential oil in carqueja. Ciência e Agrotecnologia, v.30, n.1, p.52-7, 2006.

SILVA, F.G. et al. Seasonal variability in the essential oils of wild and cultivated Baccharis trimera. Journal of the Brazilian Chemical Society, v.18, n.5, p.990-7, 2007. SIMÕES, C.M.O. et al. Farmacognosia: da planta ao medicamento. 6.ed. Porto Alegre: Editora UFRGS, 2007.1102p.

TEPE, B. et al. Screening of the antioxidative and antimicrobial properties of the essential oils of Pimpinella anisetum and Pimpinella flabellifolia from Turkey. Food Chemistry, v.97, n.4, p.719-24, 2006.

UNNIKRISHNAN, V.; NATH, B.S. Hazardous chemical in foods. Indian Journal Dairy Bioscience, v.11, p.155-8, 2002. VARDAR-ÜNLÜ, G. et al. Antimicrobial and antioxidant activity of the essential oil and methanol extracts of Thymus pectinatus Fisch. et Mey. Var. pectinatus (Lamiaceae). Journal of Agricultural and Food Chemistry, v.51, n.1, p.63-7, 2003.

VELLUTI, A. et al. Initial screening for inhibitory activity of essential oils on growth of Fusarium verticillioides, $F$. proliferatum and $F$. graminearum on maize-based agar media. Food Microbiology, v.21, n.6, p.649-56, 2004.

VILA, R. et al. Constituents of the essential oils from Piper friedrichsthalii C.DC. and P. pseudolindenii C.DC. from Central America. Flavour and Fragrance Journal, v.18, p.198-201, 2003.

ZHANG, $\mathrm{H}$. et al. Evaluation of antioxidant activity of parsley (Petroselinum crispum) essential oil and identification of its antioxidant constituents. Food Research International, v.39, n.8, p.833-9, 2006. 